\title{
Study on the Benchmarking and Optimization of Fujian International Business Environment
}

\author{
Yali Shao \\ School of Marxism \\ Fujian Jiangxia University \\ Fuzhou, China 350108
}

\begin{abstract}
Fujian optimizes the international business environment to conform to the international frontier level, which plays an important role in promoting its economic growth. According to the assessment standards and practices of World Bank's business environment, the quantitative research findings show that the international business environment in Fujian is generally good, but there are obvious shortages in the ten major areas in assessment such as long process, low efficiency and vague rules. Therefore, Fujian should seize the strategic opportunities of "the Belt and Road" to actively explore the business rules that are in line with international rules through benchmarking of the practice of international advanced cities and build a relaxed and orderly market environment, a convenient and efficient government environment, a fair and complete legal environment and open and innovative elements environment.
\end{abstract}

Keywords-internationalization; business environment; benchmarking; optimization strategy

\section{INTRODUCTION}

A good business environment is like magnet that can attracts businesses to gather and release the potential for investment and entrepreneurship. It is both the primary driving force for the expansion of regional economy aggregate and an important indicator of the core competitiveness of the region. Therefore, how to further deepen the reform, expand the opening-up, and benchmark and optimize the economic operation mechanism and system that is in line with international practice and trade rules to conform to the international frontier level has extremely important practical significance for playing the important regional advantage of Fujian to win the commanding height in a new round of local economic competition of China.

\section{THE CONCEPT AND ELEMENTS OF INTERNATIONAL BUSINESS ENVIRONMENT}

Under the background of increasingly fierce global competition, the construction of business environment has become the new focus of investment and trade in all countries in the world. China proposed in "Vision and Action

Fund Project: A General Project of Social Science Planning task in Fujian Province in 2016 "Research on Establishing a Mechanism of Fujian's Public Happiness Index focused Enhancing People's sense of gain" (Project No.: FJ2016B143). for Promoting the Building of the Silk Road Economic Belt and the Maritime Silk Road in 21st Century" that "efforts should be made to study the issue of investment and trade facilitation, trade barriers should be eliminated and a good business environment should be built in the region and various countries."[1], which means that the focus of national level on investment promotion is shifted from trading activity to the element environment related to trading activity such as politics, economy and culture and so on.

At present, consensus on the concept of Business Environment has not yet been reached in both academia and practice field. Some studies do not distinguish the concepts similar to "business environment" such as "Investment Environment" and "Marketing Environment" and so on. These concepts are often commonly used or mixed. Most directly use the concept and index system of the World Bank. The World Bank defines the business environment as "conditions such as the time, costs and legal formalities required by enterprises in complying with the local policies and regulations in establishing, manufacturing, operating, taxing, executing contracts and quit" and design the assessment indicators of business environment based on this definition. Since 2003, the World Bank has consecutively released 14 reports on the global business environment. According to the Report on Global Business Environment in 2017, New Zealand ranks the first, followed by Singapore in 190 countries and regions in the world while China ranks 78th. [2] Based on the report on Business environment of World Bank in 2005, Zhang Bo (2006) proposed that the promotion of business environment in China should be carried out step by step and promoted from two aspects of administrative reform and judicial reform [5]. Dong Zhiqiang and Wei Xiahai (2012) examined the relationship between soft environment of business system and economic development based on the data from the Report on Business environment in China in 2008 of the World Bank. At present, Guangdong Province, Fujian Province and Zhejiang Province have carried out relevant research and assessment work successively under the guidance of the concept of business environment of the World Bank.

It can be seen from the existing research results that the business environment refers to the sum of the surrounding various environments and conditions related to the whole process of the business operation (including all the links of 
start-up, expansion and operation to the end), which is an important manifestation of economic soft power and competitiveness of a country or region. The dominance of "operation" is the government, which emphasizes the responsibilities of government including guidance, coordination and planning. The "business" refers to various kinds of enterprises, including enterprises of different ownership like foreign and domestic businesses, emphasizing the main role of enterprises in economic activities. The "environment" is the overall environment integrating market environment, government environment, social environment, legal environment, element environment, and facilities environment. To build an international business environment, Fujian Province needs to start from the perspective of opening investment to set up an operation mechanism and system of market economy in line with international practice and the rules of WTO and enhance open and convenient commercial investment and trade behavior.

\section{BENCHMARKING ANALYSIS OF INTERNATIONAL BUSINESS ENVIRONMENT IN FUJIAN}

In order to comprehensively and quantitatively evaluate the international business environment in Fujian Province, taking into account the comparability and availability of data, this study assumes Fujian as an independent economic entity, collects and analyzes the data index system of Fujian Province up to January 1, 2017 according to the assessment criteria from report on Business environment in 2017 of World Bank, and compares it with Singapore to find out the gap. The results show that according to World Bank standards, international business environment Fujian is generally good, but the short board like long process, low efficiency, and vague rules are obvious, which mainly presents as follows:

First is the field of enterprise registration. Starting enterprises in Fujian Province has achieved significant results in the reform of the minimum contributed capital system, but it takes longer time with many processes. Starting an enterprise generally needs to complete 7 legal procedures including name approval, business registration of "three in one", stamp carving, opening bank account and tax registration, which takes 16 days and the average cost of completing all the procedures accounts for $3.1 \%$ of the per capita national income. It has achieved "zero yuan" registration. In Singapore, it only needs 3 procedures and takes 2.5 days, accounting for $0.6 \%$ of the cost, also "zero" registration.

Second is the field of handling construction permits. In Fujian, it takes many steps and much time-consuming and lack professional certification, ranking relatively backward level in the world. Enterprises need to pass the repeated examination of several departments including planning, land, environmental protection, construction, water conservancy, civil air defense, fire protection, water affairs, real estate and so on and go through 22 processes when handling construction permit, which takes 230 days. The approval efficiency is low and the cost accounts for $4.9 \%$ per capita income with the construction quality control index of 9 (out of 15 points). Benchmarking Singapore, it is found that only 9 procedures needed to be passed, 48 days are taken and the cost accounts for $6.1 \%$, with the construction quality control index of 12 .

Third is the field of access to electricity. In Fujian, the approval is slow with higher cost. The average number of legal steps need to be taken in obtaining electricity is seven and 81 days are taken. The average cost of completing these procedures is $84.1 \%$ of per capita national income in Fujian and the index of power supply reliability and transparency of electric charge is 6 (out of 8). In Singapore, four steps is needed, taking 30 days and the cost accounts for $25.8 \%$, with the index of power supply reliability and transparency of electric charge of 7 .

Fourth is the field of property registration. The ease of Fujian is higher than the global average, and the improvement in speed of handling time is obvious, but when the "pain points" of incapability of sharing information when handling still appear sometimes. The enterprises need to go through 4 steps that take 9 days to handle. The cost accounts for $4.1 \%$ of the financial value, and the index of the land management system quality is 22 (out of 30). In Singapore, it requires 6 steps in 4.5 days, with the cost accounting for $2.9 \%$, and the index of land management system quality is 29 (out of 30).

Fifth is the field of getting credit. Fujian has improved its enterprise credit reporting system and its convenience level is above the global average. However, the difficulty of corporate financing is still big, so the financing guarantee system remains to be completed. Among them, the credit information index increases to 8 (out of 8), and the legitimate rights index is only 5 (out of 12), which indicates that the modern asset pledge registration system in Fujian is not perfect. It is mainly due to security law and bankruptcy law of China has not yet place the property owned by enterprises in the security system, so it becomes "dead money". In Singapore, its credit information index and legitimate rights index reaches full mark.

Sixth is the field of protecting the minority investors. Fujian's convenience is at a relatively backward level in the world. Fujian's performance in the disclosure index and the company's transparency index is relatively outstanding. Interests in our country have notable effects in improving market transparency and the disclosure mechanism. However, there are clear short boards in the aspects such as the minority investor protection efforts index, dispute mediation index, disclosure index, directors' responsibility index, shareholder suitability index, shareholder governance index, shareholder rights index, ownership and management control index, and company transparency index, which undoubtedly undermine investors' trust in the corporate financing system. Compared with Singapore, the six indicators are close to full marks, showing good corporate governance rules.

Seven is the field of taxation. It takes a long time and high cost in Fujian, and convenience is at the global backward level. Enterprises in Fujian pay an average of nine kinds of taxes a year and 295 hours to apply for, prepare and pay taxes, with the total amount of tax accounting for $61.3 \%$ 
of company's gross profit. In Singapore, there are 6 kinds of taxes, only 66.5 hours of tax return time, and $18.4 \%$ of the tax rate.

Eighth is the field of cross-border trade. The convenience level of Fujian ranks middle level in the world, but there is still a great distance between the world advanced level, which is particularly reflected in the various complicated examination and approval procedures and high time cost of custom clearance. The comparison of various indicators in the cross-border trade between Fujian and Singapore is as follows: in the import trade, the document compliance time of is (48: 3) hours and the expenditure is (158: 40) U.S. dollars; the border compliance time is $(57: 35)$ hour with cost of (\$390: 220); in export trade, document compliance time is (12: 2) hours, and the cost is (35:37) U.S. dollars; border compliance time is $(45: 12)$ hour, with the cost of (392: 335) U.S. dollar.

Ninth is the field of contract enforcement. The convenience in Fujian is better than the global average. Compared with Singapore, Fujian has a greater advantage in terms of cost index (11.5\%: $25.8 \%)$, but in terms of time (235 days: 164 days) and the Judicial Process Quality Index (13 points: 15 points; out of 18 points), there is still a certain gap between the two. It can be seen that when there is a legal dispute between enterprises and suppliers or customers, it takes a long time to resolve the dispute and implement through the courts.

Tenth is the field of bankruptcy. Fujian is in line with the overall situation in China and ranks near the front in the world. It takes about 1.7 years for enterprises to restructure and convert to liquidation. The cost of bankruptcy account for $22 \%$ of the property value and the final recovery rate is only $36.9 \%$. Compared with the recovery rate of $89.7 \%$ in Singapore, the gap is very clear.

Taking into account the criteria of the ten fields of World Bank Business Environment Assessment, Fujian has generally achieved some success in eliminating bureaucratic procedures and obstacles that interfere with the operation activity of private-owned enterprises. However, the enterprises still face heavy regulatory burdens and vague business rules, resulting in large time and cost burden, so the operating efficiency of enterprises is not high, which directly undermines the regional competitiveness of Fujian and limits the potential of enterprises to create jobs.

\section{OPTIMIZATION STRATEGY FOR FUJIAN INTERNATIONAL BUSINESS ENVIRONMENT}

Under the national strategy of "the Belt and Road", to create a high standard international first-class business environment and attract and expand investment from the countries along the line in Fujian not only requires innate geographical conditions but also needs comprehensive factors of multiple aspects including government administration, social culture and production factors. Therefore, Fujian should seize the strategic opportunities of "the Belt and Road" to promote the transformation of government functions and take the road of optimizing the business environment with Fujian characteristics.

\section{A. Benchmarking the First Class to Build a Relaxed and Orderly Market Environment}

1) To improve market access mechanism: We should vigorously promote the facilitation of registration of commercial subjects, relax the maximum market access conditions, and reduce the threshold for investment and entrepreneurship of the market subjects. In the process of approval of enterprise name, experience of registration reform of enterprise name in Shanghai FTZ can be learnt from to improve the self-declaration system of enterprise name, realize the approval of the registered name within one day, and finally cancel the pre-approval of the enterprise name so as to effectively solve the "pain points" the enterprises reflect including difficulty in checking name, tardiness of checking name, and incapability in meeting the individual needs of the name.

2) To improve market service capabilities: We should support various business associations and promotion agencies to hold various forms of market service promotion activities. Besides, we can build a market service and public service platform in the form of government procurement and introduce a public service platform for assessment methods of enterprise satisfaction where an independent third party evaluates the performance of the public service platform as an important basis for subsequent purchase of services. We can also create and improve a comprehensive service platform for medium small and micro-sized enterprises integrating multiple functions and services, and hold a variety of theme activities such as forum salons, public welfare trainings, exchange meetings and matchmaking meetings to fully serve the medium small and micro-sized enterprises.

3) To construct market supervision system: We should learn from the international practices and common practices to improve the public credit information platform of the province. The government should strive to take the lead in completing the conversion and use of the national unified credit code, and integrating provincial and municipal enterprise credit information system, personal credit reporting system, relevant government departments and social institutions database to build a public credit information platform integrating the base data of credit information of enterprises, individuals, institutions and social organizations in the province. We can promote the sharing of information of supervision and punishment of various departments to form a comprehensive market credit regulatory system, providing the whole society with the service of unified release of public credit information, anomaly publicity, facilitation of inquiry and opposition handling and so on. Enterprises should be encouraged to put their own behavior under the supervision of the public and regulatory authorities. For example, the project of "transparent kitchen" can be fully promoted in catering enterprises, so that regulators and consumers can see realtime scenes in the kitchen. 


\section{B. To Advance with the Times to Build a Convenient and Efficient Government Environment}

1) To deepen the reform of decentralization: The government should definitize the boundaries of government functions, and streamline the internal circulation links, reengineering work processes through methods of merger and reduction, so that everything be simplified, the never connect one that can be connected in parallel in series, and never posit the one that can be posited backward front. Thus we can strictly regulate and reduce the approval procedures to optimize the administrative examination and approval procedures and relax market subjects to the utmost extent. We need to adjust the merged examination and approval items, simplify and merge the various examination and approval items involved in the complicated investment and construction projects from project approval to completion acceptance, and simplify the procedures and formalities for administrative examination and approval to implement the absent acquiescence and mechanism of overtime acquiescence to strengthen the supervision and administration.

2) To improve the efficiency of government services: We can compress the time limit for administrative examination and approval to improve the efficiency of administrative services. By learning from international practices, we can fully implement the "one card acceptance" in enterprise electric power, simplify the requirements for electric power, and shorten the circulation time of all aspects; Transform the requirement of providing the construction project planning permits, business licenses and other elements when handling the business originally to providing any one of valid documents to complete the acceptance on the spot. Moreover, we need to fully implement the "one single window" in cross-border trade, achieve "one window, one platform, one declaration, and one settlement" paperless declaration throughout the process. People can always update and check the status of the customs clearance of goods.

3) Full implementation of e-government: Attention should be paid to the innovation of government affairs services to create a one-stop, intelligent, and systematic government service model. We can promote e-government to infiltrate into all aspects of business services and carry out the paperless and one window for acceptance reform measures in the departments of customs, taxation, and business and so on. We should learn from Singapore to comprehensively build electronic enterprises registration system, integrate the procedures for the application of enterprises to achieve synchronized collaboration of multiple departments, so that entrepreneurs can apply a license online through the "one application, one payment" no matter when and where, which can reduce the application time and costs.

\section{Institutional Innovation to Build a Fair and Perfect Legal Environment}

1) To improve the legal system of business environment: Based on the exploration of the legislation of Fujian FTZ first docking the international rules, we can consolidate and popularize the experience of reform and innovation through laws and regulations and establish an international commercial arbitration and international commercial mediation system that is in line with international standards. In addition, we can learn from the experience of Hong Kong to promote the diversified drafting mechanism for laws and regulations, improve the content of laws and regulations in terms of practical operation, definition of power and responsibility, and procedure setting and so on. And we can encourage cross-strait law firms to associate and exchange legal advisers to provide legal services for financial innovation and dispute resolution in the province. We can also effectively protect the personal rights and property rights of enterprises and entrepreneurs through the rule of law, and include the operation of market players in a systematic, standardized and legalized track.

2) To improve the fair and civilized law enforcement system: Learning from the achievements of the reform in Fujian Free Trade Zone, we should constantly improve and optimize the law enforcement procedures of administrative law execution departments at all levels. Thus we can explore the diversified dispute resolution approach, promote the reform of the operating mechanism of judicial power, reform of expert consultants and jury mechanisms to provide high-quality law enforcement services for the construction of Fujian under the rule of law. We will promote the construction of an online administrative law enforcement platform and supervise the executive authorities to exercise their powers in strict accordance with the power list and perform their duties in accordance with the responsibility list, so as to achieve "administrative power into the list and no authority beyond the list" and fully implement the responsibility system for administrative enforcement of law.

3) To improve the fair judicial operation system: We can promote the publicity of trial, prosecutorial work and police affairs relying on information means, publicize the judicial bases, procedures, process, results and effective legal documents according to law in time, and strengthen supervision on law enforcement and judicature. We will thoroughly implement the work style inspection and case evaluation system to strengthen the legal supervision of procuratorial organs and resolutely prevent abuse of law enforcement powers. We need to improve the judicial work mechanism of service of documents and investigation and evidence collection, and increase the construction of information sharing platform of administrative departments and judicial departments. 
D. To Integrate Resource and Build an Open and Innovative Element Environment

1) To gather talents in shortage: We can vigorously introduce leading talents for innovation and entrepreneurship and high-level talents at home and abroad, and guide the high-end and high-quality talent resources flow to key regions, key industries, key enterprises and key projects through the policy treatment and high reward of settling down and children education. Besides, we can make efforts to address the problem of children education and oldage pension of first-line scarce technical talents, and strengthen targeted service measures including education, health care, and elderly service to provide convenience for them to work in Fujian. Learning from Singapore's experience, we can increase the training of skilled personnel needed for the transformation and upgrading of traditional industries, design evaluation indicators, insist on results orientation, and subsidize enterprises to carry out personnel training.

2) To Strengthen corporate financing services: The financial service system should be gradually formed based on a sound credit system, with complete market service of credit, equity, bonds, trusts, guarantees, insurance, and pawn. We need to improve the financing guarantee system, and build a government-led financial guarantee system linking province, city and county. We will speed up the construction of cross-strait regional financial service centers, promote the gathering of various types of financial innovation formats, and foster and develop the financial elements market to enhance the guarantee ability of financial services. Learning from the practices of Guangdong, we can set up a "credit cloud" platform that connects social credit system and corporate financing to improve the success rate of financing of high-quality and honest small and medium-sized enterprises and reduce the financing cost.

3) To Enhance the level of industrial support: We can increase financial input and cross-level and crossdepartmental synergistic efforts to accelerate the process of industrialization of innovative technology by integrating support fund of industries and forming work synergies, and rapidly form industrial support. Thus demonstration effects can be formed rapidly and expand to other fields and regions through pilot applications in the subdivision areas. In addition, we should encourage large and medium-sized enterprises to drive the concentrated development of small and micro enterprises in the industrial chain, guide the small and micro enterprises to gather and develop in industrial parks, promote the construction of venture capital investment gathering place and enhance the value of supporting industries.

\section{CONCLUSION}

In short, Fujian has a series of pilot preferential policy advantages such as the core area of the Maritime Silk Road in the 21 st century, the free trade pilot area of China (Fujian), the comprehensive experimental area of Pingtan, and the economic zone on the west side of the Taiwan Strait. The strategic layout of "multi-area superposition" promotes Fujian's reform and opening up move towards a new height. In the next five years, Fujian can continue to amplify the institutional innovation effect, benchmark the practice of international advanced cities, actively explore business rules in line with international rules, and improve a relaxed and efficient business environment to eventually get closer to the world class.

\section{REFERENCES}

[1] National Development and Reform Commission, Ministry of Foreign Affairs, and Ministry of Commerce. The vision and action of promoting the building of the Silk Road Economic Belt and the 21st Century Maritime Silk Road.[EB/OL].http://news.xinhuanet.com/world/201503/28/c_1114793986.htm 2015-03-28.

[2] The World Bank. Report on Global Business Environment. [EB/OL].http://chinese.doingbusiness.org/.

[3] Zhang Bo. Comparison of International Business Environment Indicators and China's Countermeasures. Economic Review, 2006(5):62-65.

[4] Dong Zhiqiang, Wei Xiahai, Tang Canqing. Institutional Soft Environment and Economic Development: An Empirical Study Based on the Business Environment in 30 Big Cities. Management world, 2012,(4): 9-20 